\title{
MODELLING OF TIMBER I-BEAMS IN BENDING
}

\author{
M. LI ${ }^{1}$, V.D. THI ${ }^{1}$, M. KHELIFA ${ }^{2}$ \& M. EL GANAOUI ${ }^{1}$ \\ ${ }^{1}$ University of Lorraine, LERMAB, EA 4370, IUT de Longwy, 54400 Cosnes et Romain, France. \\ ${ }^{2}$ University of Lorraine, LERMAB, EA 4370, 27 rue Philippe Séguin, CS 60036, 88026 Epinal, France.
}

\begin{abstract}
A 3D Finite Element (FE) model has been developed, which accounted the geometric nonlinearity of flange and web portions of I-beams. The nonlinear FE model was reviewed against tests on castellated timber beams having a web with hexagonal holes. Load carrying capacity, load-deflection responses and failure modes for castellated beams in flexure were predicted and compared to the experimental results. An additional parametric study involving two different web opening shapes (circular and rectangular) was performed using the presented FE model to study the effects of the change of shapes of holes in web portions on the strength and buckling behaviour of castellated beams in bending. The parametric study has shown that castellated timber beams failing due to web-post buckling modes exhibited a strong decrease in the initial load capacity.

Keywords: bending test, buckling behaviour, FE model, geometric nonlinearity, parametric study, timber I-beams.
\end{abstract}

\section{INTRODUCTION}

Castellated timber beams are commonly used in modern timber constructions to cover long spans as primary structural elements in floor and roof applications [1,2]. This is attributed to the fact that castellated beams generate flexibility in the use of the roof area, greater flexural stiffness and higher load carrying capacity, economic construction, optimum self-weightdepth ratio and good aesthetic architectural appearance. Although, the flexural behaviour of castellated beams was sufficiently analysed in the linear elastic field, investigations highlighting the mechanical strength and failure modes of castellated timber I-beams as well as interaction of buckling modes for I-beams are rarely found in the literature. Moreover, to date, there are no design guides for timber castellated beams under torsional buckling leading to the current investigation.

In literature, some studies on the nonlinear mechanical behaviour of timber castellated beams under bending tests were reviewed, and different associated failure modes were pointed. A few of these phenomena do not occur for timber I-beams without web openings since they are a direct result of the distinct way in which shear is propagated through the perforated web. Two different failure modes of castellated timber I-joists were formed either by shear failure at finger joint due to web distortional or by tensile failure at the corner of openings, as reported by Harte A.M. and Baylor G. in refs [1, 2]. Previous numerical methods to predict the ultimate loads at which each of these types of failures occurs were evaluated against the available experimental data without taking into account the adhesive constitutive law, including the bond-slip actions at the finger joint interface. Currently available approaches to predict the rupture that can appear on timber castellated beams in bending, while rather less accurate, are not adequate for design, and the limitations of these methods are thus discussed in this work.

The experimental work presented in refs $[1,2]$ comprised a series of full scale destructive tests on simply supported castellated beams subjected to four-point bending tests. The failure modes were dominated by the tension and shear mechanisms. The effect on the failure load owing to the presence of web stiffeners under the point loads was investigated. The tests 
were loaded until rupture and failure modes were recorded. Based on the experimental tests $[1,2]$, it was noticed that the use of full height web stiffeners at the location of point loads has a considerable effect on the strength of castellated beams and the effect of the buckling modes can be neglected. The studies detailed in $[1,2]$ have provided useful information regarding the ultimate loads and failure modes of castellated timber beams that could be used in developing nonlinear FE models taking into account the torsional buckling, which is addressed in this study. Information regarding the nonlinear elastic buckling behaviour of timber castellated beam was not investigated in literature; to date, it is still unknown how the interaction of torsional and distortional buckling behaviour would affect the strength and inelastic mechanical behaviour of castellated beams. The article also aims at evaluating these aspects.

Like the use of castellated webs in timber I-beams is a new concept, there have been few studies published on their flexural structural behaviour [1,2]. Most studies were performed on castellated steel beams. A number of different failure modes have been identified for cellular steel beams including the web buckling-post and distortional buckling [3]. Ellobody (2012) [3] found that the failure modes of cellular steel beams were sensitive to the torsional buckling. He used a numerical model to investigate the cellular steel beams under combined buckling modes, and where the initial geometric imperfection, residual stresses and nonlinear material properties of cellular steel beams have been incorporated into the FE model. Liu and Chung (2003) [4] used an FE model to analyse the influence of opening depth and beam size on the structural performance of steel castellated beams. They found that the failure modes were similar for the different sizes and shape openings. Zirakian and Showkati (2006) [5] studied the distortional buckling of steel castellated beams. The tested beams underwent buckling accompanied by web distortion.

The purpose of this study is thus to develop an efficient nonlinear FE model emphasizing the effect of buckling modes in castellated timber beams under flexural behaviour. The nonlinear FE model takes into account the adhesive properties and the inelastic material constants of flange and web portions of castellated beams and the geometric nonlinearity. The global response, in terms of load and displacement, and the failure modes were predicted and compared to experimental tests published in refs $[1,2]$. An additional parametric study was carried to analyse the effect of change of web opening shapes on the mechanical strength and buckling behaviour of timber castellated beams.

\section{MANUFACTURE OF CASTELLATED BEAM AND GEOMETRIC CONFIGURATION OF WEB OPENINGS}

Generally, the castellated beams are produced by automatically cutting and connecting the flange and web portions of I-beams using an adhesive joint as illustrated in Fig. 1. Since the depth is increased about 50\% as shown in Fig. 1 (more if the web plates are inserted between the two resulting parts), the obtained cross-section has a bigger bending stiffness.

According to Kerdal and Nethercott [6], the presence of the web holes not only changes the relative importance of possible failure modes, but it also introduces the possibility of appearance of additional modes. It is the main aim of this work to review previous studies $[1,2]$ dedicated to analyse the flexural behaviour of castellated beams in order to identify the various failure modes and, where possible, provide suggestions for the most suitable method of designing castellated timber beams.

The presence of regularly spaced web holes means that the castellated beams act like an assembly of single-structural components, where the horizontal chord members consist of the 

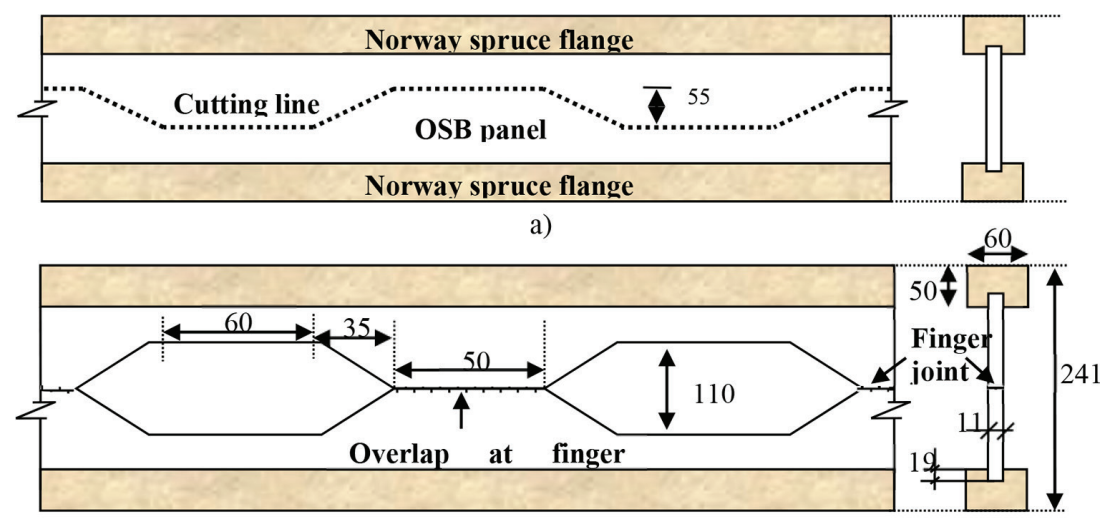

b)

Figure 1: Manufacture of castellated beam: (a) burning pattern; (b) castellated beam formed (not scale and dimensions in $[\mathrm{mm}]$ ).

tee-section spanning between the holes. For instance, at a hexagonal cross-section, the shear must be spread by the bending behaviour of the tee-section constituted by the flange portion and the remaining part of the web adjacent to the flange. Figure 2 shows that the external shear force was divided equally between the upper and lower chords, and acts at the points of contra-flexure.

The need to use castellated beams as structural elements in timber construction for the purpose of calculating the values of shear forces emerged from a number of studies available in literature in which the test arrangement was designed to ensure that only an in-plane response of the beam was possible as reported by Kerdal and Nethercott (1984) in [6]. In our opinion, this approach contains certain limitations. Thus the mechanical strength of each component of castellated beams had to be checked and the proposed FE model will be discussed in this study.

When castellated beams are not laterally restrained, it is necessary to consider buckling behaviour as a potential failure mode. This issue was not addressed to date for wooden I-beams. Because of the need to ensure that failure of the tested castellated beams actually occurred by torsional and distortional buckling modes, it was necessary to examine all possible modes of failure. The work presented here is considered as a first step towards an investigation of this problem.

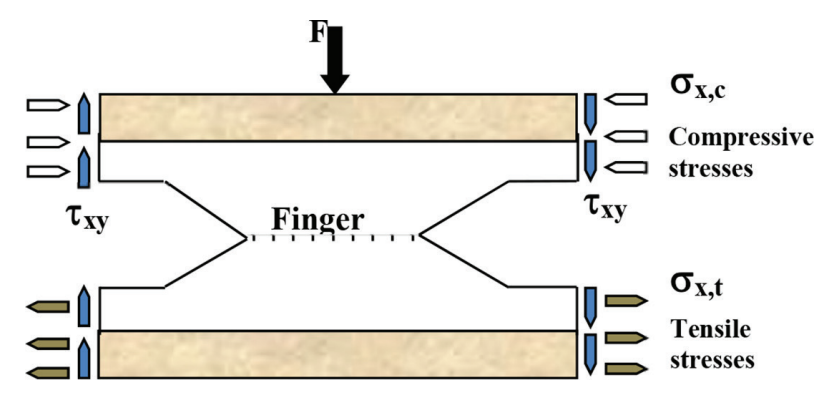

Figure 2: Distribution of stresses. 


\section{RUPTURE OF THE ADHESIVE JOINT}

Each separate web section is then bonded to the top and bottom flanges using a Phenol Resorcinol Formaldehyde (PRF) adhesive to produce a cross-section of castellated beam shown in Fig. 1b. According to the authors Raftery and Harte (2013, see ref [7]), the PRF adhesive also obtained excellent results with the timber in refs $[8,9]$.

In this article, the surface-based cohesive behaviour was used to model the adhesive interaction between different portions composing the castellated beams. This method is easier to use since there is no need to create additional elements as pointed in our previous studies $[10,11]$. The thickness of an adhesive layer is negligibly small. Therefore, this method is more appropriate to simulate the different adhesive interfaces (Norway Spruce flange-OSB panel and OSB-OSB) because it can significantly reduce computational cost compared to the second method, available in Abaqus [12], using the cohesive elements.

Figure 3 shows a graphic illustration of a simple bilinear traction-separation law written in terms of the nominal stress $\sigma_{i=\text { I,II }}$ and effective opening separation $\delta_{i=I, I I}$. The interface is modelled as an adhesive layer with small thickness and the initial elastic stiffness $\mathrm{K}_{\mathrm{i}=\mathrm{I}, \mathrm{II}}$ is defined as $[10,11]$ :

The initiation of damage was assumed to occur when a quadratic traction function involving the nominal stress ratios reached value one. This criterion can be rewritten as:

$$
\left[\frac{\sigma_{\mathrm{n}}^{\mathrm{I}}}{\sigma_{0, \mathrm{n}}^{\mathrm{I}}}\right]^{2}+\left[\frac{\sigma_{\mathrm{t}}^{\mathrm{II}}}{\sigma_{0, \mathrm{t}}^{\mathrm{II}}}\right]^{2}=1
$$

where $\sigma_{0, \mathrm{n}}^{\mathrm{I}}$ and $\sigma_{0, \mathrm{t}}^{\mathrm{II}}$ are the maximum cohesive strengths in I and II modes respectively.

For the presented cohesive model, the adhesive parameters are the maximum cohesive strengths $\left(\sigma_{0, \mathrm{n}}^{\mathrm{I}}\right.$ and $\left.\sigma_{0, \mathrm{t}}^{\mathrm{II}}\right)$, the initial stiffness $\left(K_{n}\right.$ and $\left.K_{t}\right)$ and the maximum separations $\left(\delta_{n, \max }^{I}\right.$ and $\left.\delta_{t, \text { max }}^{I I}\right)$. The cohesive parameters used for this study were recapitulated in Table 1.

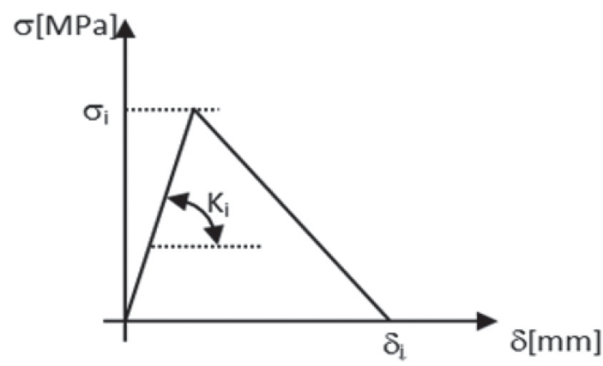

Figure 3: Traction-separation cohesive material law.

Table 1: Cohesive parameters in pure modes I and II.

\begin{tabular}{ll}
\hline Mode I & Mode II \\
\hline$\sigma_{0, n}^{I}=2.1 \mathrm{MPa}$ & $\sigma_{0, t}^{I I}=10.1 \mathrm{MPa}$ \\
$K_{n}=5.3 \mathrm{~N} / \mathrm{mm}^{3}$ & $K_{t}=27 \mathrm{~N} / \mathrm{mm}^{3}$ \\
$\delta_{n, \max }^{I}=5 \times 10^{-3} \mathrm{~mm}$ & $\delta_{t, \text { max }}^{I I}=5 \times 10^{-5} \mathrm{~mm}$ \\
\hline
\end{tabular}




\section{FE MODELLING}

The FEM package Abaqus/standard [12] used for this analysis was performed to model the linear and nonlinear elastic behaviours of the castellated timber beams.

The FE model analysis used for this study presents a behaviour governed by the geometrical nonlinearity. Hence, the application of boundary conditions is very important. Using an exact symmetry in loading, geometry and boundary conditions, only half of the beam was modelled as shown in Fig. 4. An 8-node solid element with reduced integration C3D8R was used to model the flanges and web of the castellated timber beams. The C3D8R element has three degrees of freedom per node and provides accurate solutions to most simulated examples.

In order to choose the FE mesh that provides accurate results using minimum computational time, convergence studies were conducted. It is found that the square mesh element with $10 \mathrm{~mm}$ size provides adequate accuracy in modelling the web and the flange of I-beams. Table 2 shows the number of elements and CPU time.

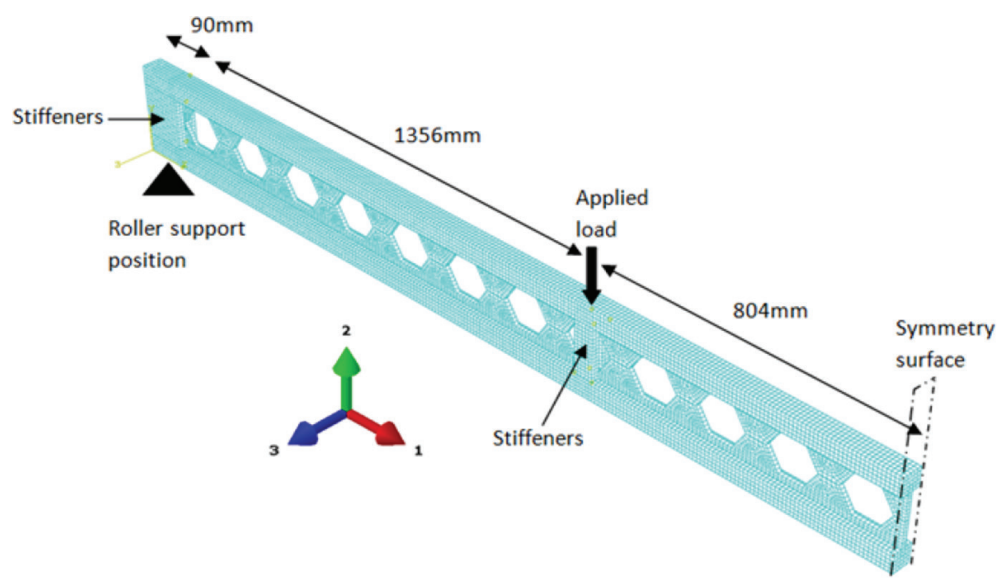

Figure 4: FE model for castellated beams with hexagonal holes.

Table 2: Model size and computational time.

\begin{tabular}{|c|c|c|c|c|}
\hline \multicolumn{2}{|c|}{ FE for castellated beams } & \multirow{2}{*}{$\begin{array}{l}\text { Number of } \\
\text { elements }\end{array}$} & \multicolumn{2}{|c|}{$\begin{array}{l}\text { CPU time (min) per analysis } \\
\text { type }\end{array}$} \\
\hline \multicolumn{2}{|l|}{ Type of holes: } & & Linear & Nonlinear \\
\hline & Flange portion & 10442 & & \\
\hline \multirow{3}{*}{ Hexagonal } & Web portion & 3540 & 01:40 & $03: 52$ \\
\hline & Web stiffeners & 952 & & \\
\hline & Flange portion & 10442 & & \\
\hline \multirow[t]{3}{*}{ Circular } & Web portion & 3102 & $01: 37$ & $03: 27$ \\
\hline & Web stiffeners & 952 & & \\
\hline & Flange portion & 10442 & & \\
\hline \multirow[t]{2}{*}{ Rectangular } & Web portion & 3840 & $01: 47$ & $03: 47$ \\
\hline & Web stiffeners & 952 & & \\
\hline
\end{tabular}


Table 3: Material properties used in simulations.

\begin{tabular}{lll}
\hline Elastic proprieties & Norway Spruce & OSB \\
\hline $\mathrm{E}_{1}[\mathrm{MPa}]$ & 11750 & 4100 \\
$\mathrm{E}_{2}=\mathrm{E}_{3}[\mathrm{MPa}]$ & 730 & 3450 \\
$\mathrm{G}_{12}=\mathrm{G}_{13}[\mathrm{MPa}]$ & 650 & 1370 \\
$\mathrm{G}_{23}[\mathrm{MPa}]$ & 70 & 130 \\
$\mathrm{v}_{12}=v_{13}$ & 0.37 & 0.31 \\
$\mathrm{v}_{23}$ & 0.42 & 0.34 \\
\hline
\end{tabular}

The material properties of the web and flange portions used in the FE model are listed in Table 3. The cross-section dimensions of castellated beams taken in all simulations are given in Fig. 1b.

\section{MODEL CALIBRATION AND VALIDATION}

In order to verify the FE model, the castellated timber beam tests detailed in $[1,2]$ were modelled. The I-beams had failure modes for full-scale tests, which ensured that the model is capable to predict the elastic flexural behaviour of a wide range of castellated timber beams. The ultimate loads, failure modes and load-midspan deflection curves observed experimentally were compared with that obtained numerically using the proposed FE model.

The load-deflection curves obtained for castellated timber beams from experiments $[1,2]$ and FE analysis are shown in Fig. 5. Good agreement is observed between the experimental and numerical results. Furthermore, the FE model is accurate enough to perform static analyses and evaluate the base shear force capacity of castellated beams. The difference in rigidity is a result of the definition of the roller offsets at the support position of the beams in the FE model.

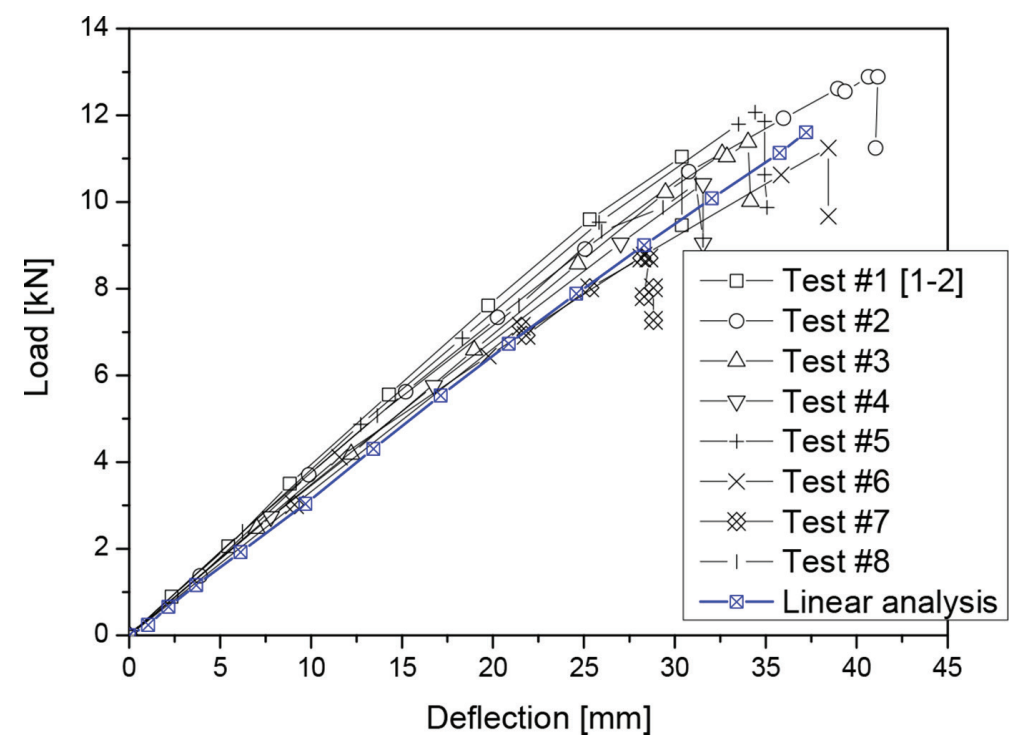

Figure 5: Comparison of load-midspan deflection curves for tested specimens. 
Table 4: Comparison of FE results with experimental tests.

\begin{tabular}{llll}
\hline Specimen & $\mathrm{F}_{\text {exp }}[\mathrm{kN}]$ & $\mathrm{F}_{\text {num }}[\mathrm{kN}]$ & $\mathrm{F}_{\text {exp }} / \mathrm{F}_{\text {num }}$ \\
\hline Test \#1 & 11.062 & 11.607 & 0.953 \\
Test \#2 & 12.910 & & 1.112 \\
Test \#3 & 11.439 & & 0.985 \\
Test \#4 & 10.410 & & 0.896 \\
Test \#5 & 12.086 & & 1.041 \\
Test \#6 & 11.267 & & 0.970 \\
Test \#7 & 8.804 & & 0.758 \\
Test \#8 & 11.127 & & 0.958 \\
\hline
\end{tabular}

The simulations and the test results for the castellated beams in bending are summarized in Table 4. Table 4 shows that the proposed FE model gives relatively accurate results.

Figure 6 depicts the principal stress distribution of the castellated beams at the end of the testing. Principal stresses are clearly concentrated and divided equally in the upper and lower chords, while they remain equal to zero at the neutral axis. The compressive stresses act in the upper chord, whereas tension stresses concentrate in the lower chord as shown in Fig. 6b. The maximum principal stress of castellated beams varied between $24 \mathrm{MPa}$ and $41 \mathrm{MPa}$, and the plastic strains are not observed.

Furthermore, the deformed shapes of timber castellated beams at failure observed experimentally and numerically were analysed. Figure 7 shows an example of the damaged zone of I-beam observed in the surrounded area in comparison with that predicted from the FE analysis. It can be seen that the predicted and experimental ruptures are in good agreement.

The tension failure mode observed experimentally was confirmed numerically as illustrated in Fig. 7a. The data obtained from Abaqus [12] has shown that the tensile stresses reach the maximum values at the top and bottom of the corner of opening under the ultimate load. The second shear failure mode, shown in Fig. 7b, of web gluing between openings has also been found and reported in literature [1,2]. It is probably due to the presence of the web buckling during the tests.

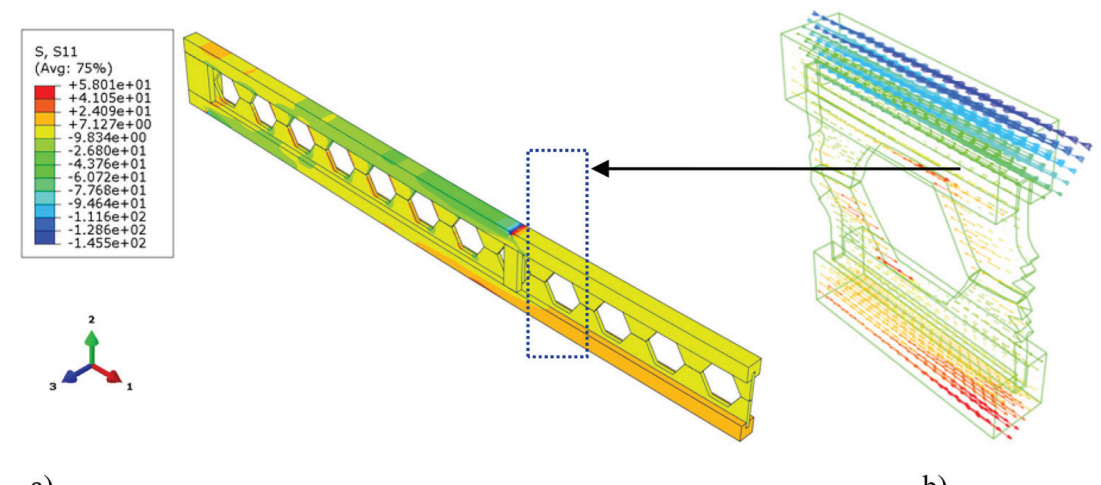

a)

b)

Figure 6: Principal stress contours at failure: (a) in castellated beam and (b) in element. 


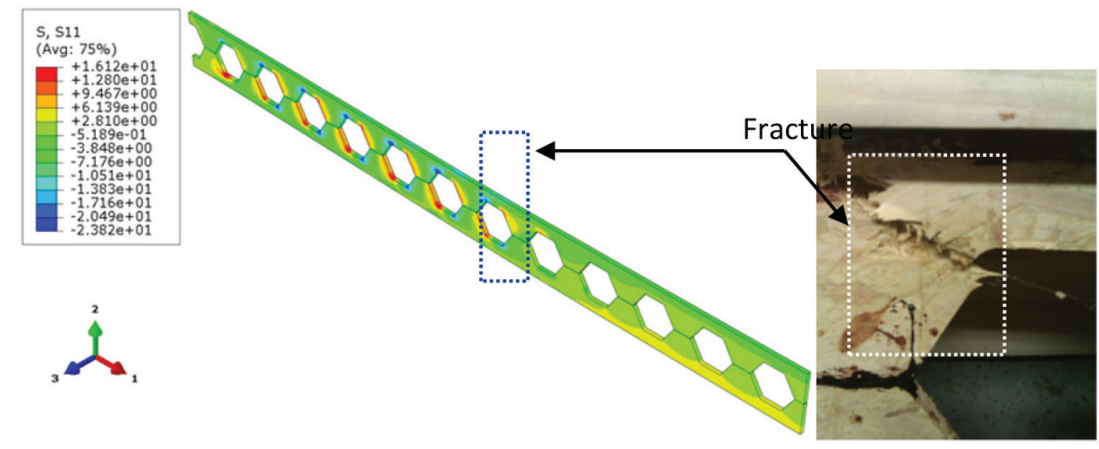

a)

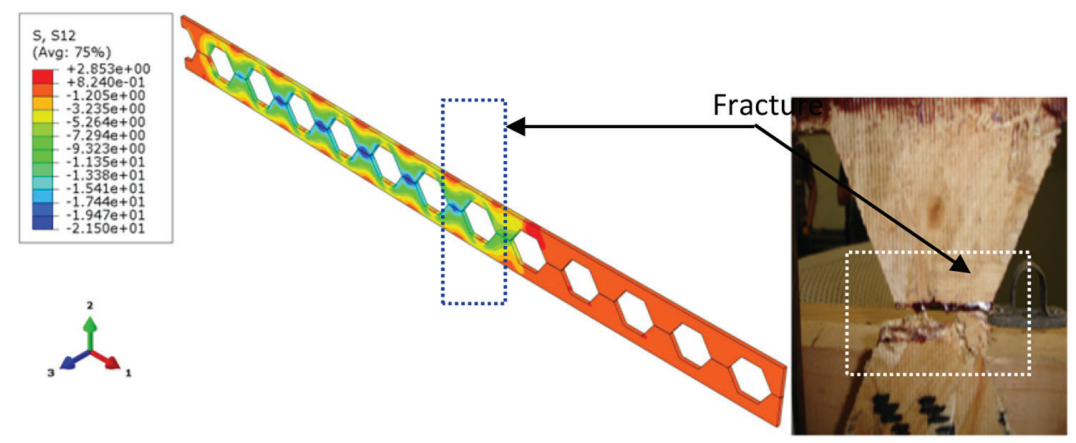

b)

Figure 7: Comparison of experimental and numerical deformed shapes at rupture for specimens tested in [1, 2]: (a) Tension failure at corner of opening and (b) Shear failure at finger joint.

In the web portion of castellated beams, the maximum first principal stress at the hole corners reaches $16.2 \mathrm{MPa}$ and the maximum shear stress at the finger joint is around $22 \mathrm{MPa}$.

\section{PARAMETRIC STUDY}

The verified FE model was used to analyse the effects of the change of section shapes of holes in the web portions on the flexural strength and buckling behaviour of castellated timber beams. The web openings with circular and rectangular holes were modelled for having the same area ratio as for castellated timber beams with hexagonal holes analysed in previous section. Table 2 and Fig. 8 summarize the FE models used for castellated beams with different web openings. All boundary and testing conditions were kept identical to those of the FE model, presented in Fig. 4, as accurate comparison was the ultimate goal.

The modelling of the buckling behaviour for castellated timber beams was developed based on a 'strut' analogy as schematically shown in Fig. 9 in which the compressive and tensile stresses act across the web-post on opposite diagonals. Initial failure occurred when a local web buckle formed adjacent to the web opening as illustrated with the shaded areas in Fig. 9. 


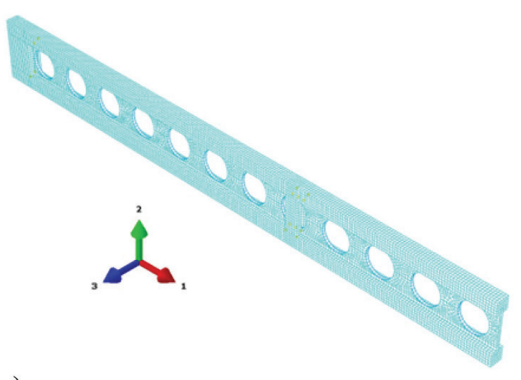

a)

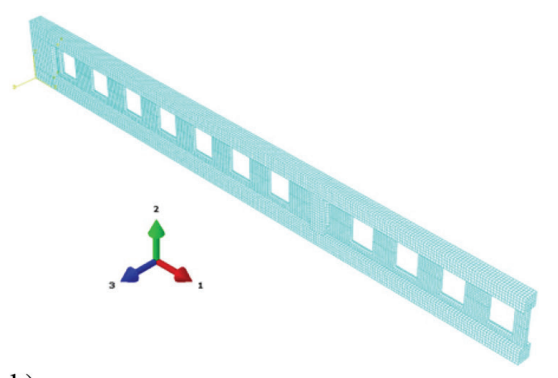

b)

Figure 8: FE models for castellated beams with: (a) circular and (b) rectangular holes.

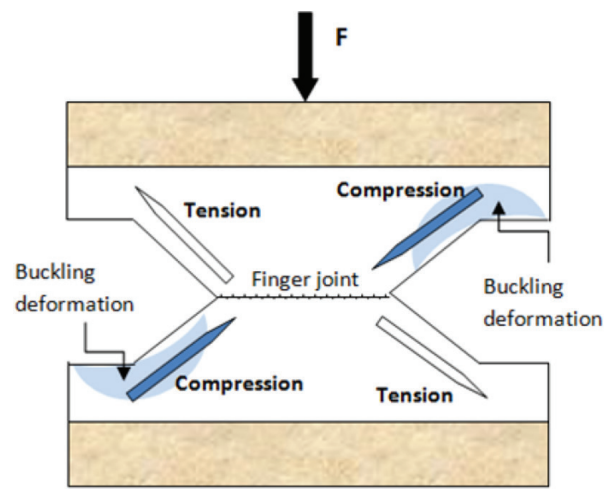

Figure 9: Typical web-post behaviour.

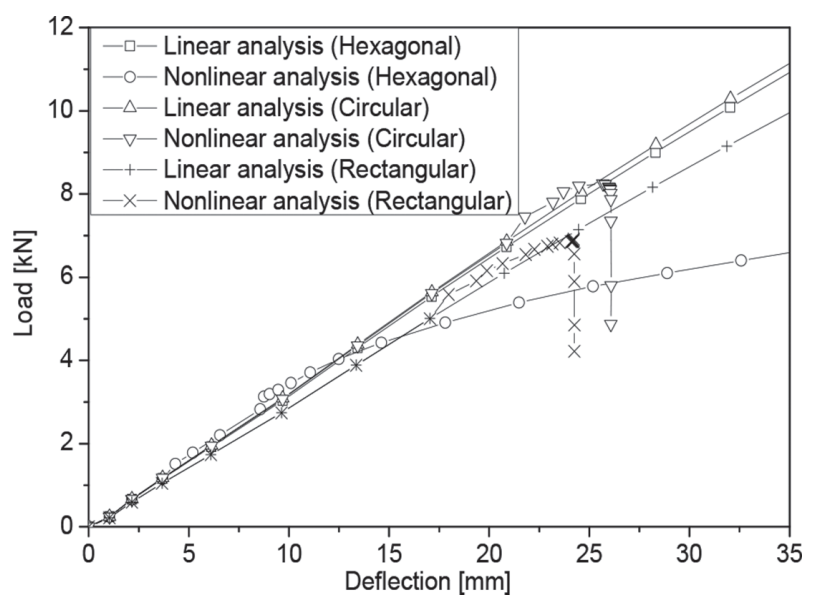

Figure 10: Comparison of load-midspan deflection curves for analysed castellated beams.

The predicted load-midspan deflection curves for all castellated beams in bending with different shapes of holes are shown in Fig. 10. For all FE linear analyses without buckling, each curve comprised only linear part as shown in Fig. 10. The elastic flexural stiffnesses of the castellated timber beams predicted from the FE analyses are summarized in Table 5. A 
Table 5: Flexural stiffnesses predicted from FE analysis.

\begin{tabular}{llcc}
\hline Flexural rigidity & Hexagonal & Circular & Rectangular \\
\hline $\mathrm{K}[\mathrm{N} / \mathrm{mm}]$ & 317.96 & 324.21 & 287.64 \\
Error $=\frac{K_{i}-K_{H E X}}{K_{H E X}}[\%]$ & - & 1.9 & 9.5 \\
\hline
\end{tabular}

good correlation can be observed between the results obtained for castellated beams with hexagonal and circular holes as reported in Fig. 10 and Table 5. At vertical deflection $v=35$ $\mathrm{mm}$, the FE model of the castellated beams with hexagonal holes gives a lower stiffness than the I-beams with circular holes. The slight difference between the flexural stiffnesses predicted is around $1.9 \%$. At the same vertical displacement, the castellated beams with rectangular holes give a flexural stiffness of $287.64 \mathrm{~N} / \mathrm{mm}$, which is $9.5 \%$ lower than the I-beams with hexagonal holes.

Looking at Fig. 10 and Table 5, it can be seen that the mechanical behaviour of the castellated timber beams depends on the shapes of the web openings, in which the FE model is able to predict the same flexural behaviour of the castellated beams using hexagonal and/or circular holes.

For all nonlinear analyses of the castellated timber beams under torsional buckling, each curve comprised linear and nonlinear parts as shown in Fig. 10. The effect of the maximum amplitude on the load versus deflection was also discussed for all specimens. As can be shown from Fig. 10, the initial imperfection has a significant effect on the load versus deflection curves of these beams.

The critical loads were evaluated by elastic finite element bifurcation analysis; yielding effect was not considered. Because of the slenderness of the beam webs, it was assumed that the beams would fail by elastic buckling before yielding occurs in the web-post. The critical and failure loads obtained from the FEM analysis are recapitulated in Table 6. It can be seen that the use of castellated beams with circular holes offered a considerable increase in the critical loads of timber I-beams involving different web opening shapes.

The principal stresses in direction (1-1) for all castellated timber beams under buckling, were also plotted in Fig. 11. It can be seen that stresses at the web regions exceeded the compressive stress of 23MPa for I-beams with circular and rectangular holes, and the compressive stress of 19MPa for those having hexagonal holes. As a result, the I-beams with circular and rectangular holes present a highly distorted web portion compared to the category of specimens with hexagonal holes. It can be concluded that the shape of web openings, and not the web opening area, affects the I-beam's behaviour in bending. Highly distorted web portions are shown in Fig. 11c.

Table 6: Critical load values from nonlinear EF analysis.

\begin{tabular}{lll}
\hline Castellated beams & $\mathrm{F}_{\mathrm{FEA}}[\mathrm{kN}]$ & $\mathrm{F}_{\mathrm{FEA}} / \mathrm{F}_{\mathrm{CIR}}$ \\
\hline Hexagonal & 2.735 & 0.39 \\
Circular & 6.841 & 1 \\
Rectangular & 4.934 & 0.72 \\
\hline
\end{tabular}




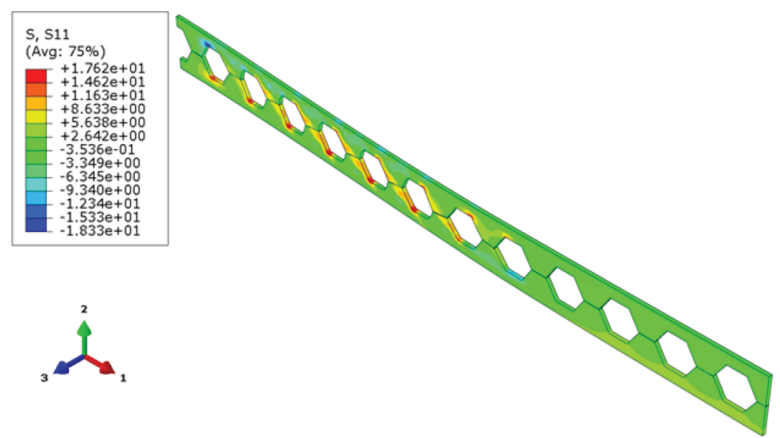

a)

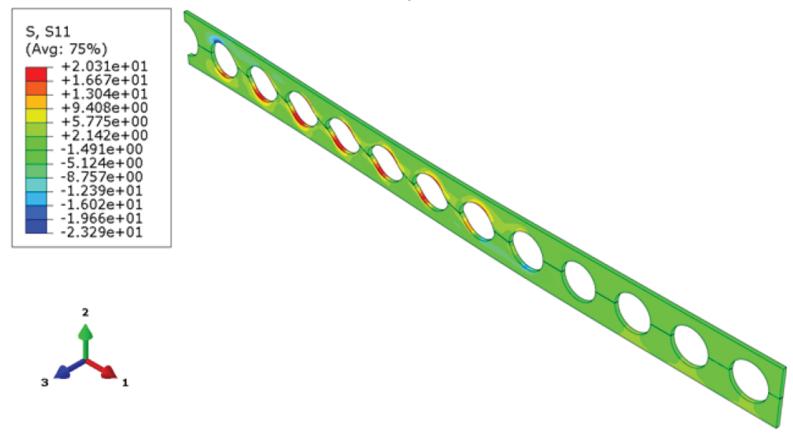

b)

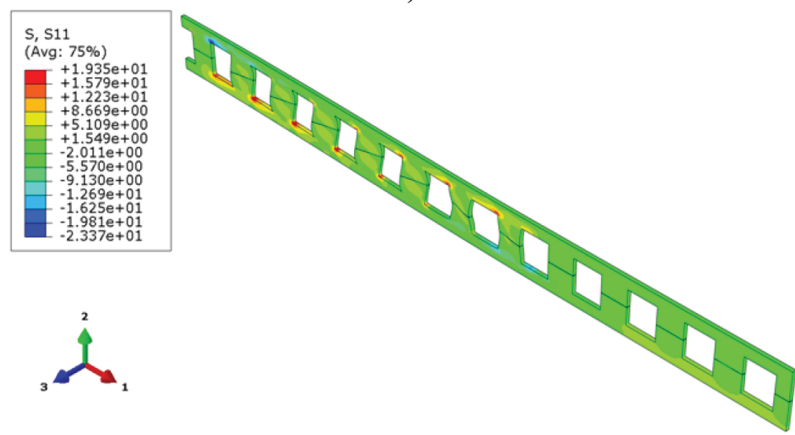

c)

Figure 11: Numerical buckled shapes at failure for castellated beams with: (a) hexagonal, (b) circular and (c) rectangular holes.

\section{CONCLUSIONS}

FE models have been developed in this study and can be used to successfully simulate the inelastic flexural behaviour of simply supported castellated timber beams with different shapes of web openings.

First, the load-deflection relationships, deformed shapes at failure and failure modes of castellated beams were evaluated by the linear FE analysis. Examples of tension and shear failure modes commonly reported in the literature have been analysed and discussed. For the elastic linear behaviour, there was no evidence of web buckling during bending tests as has been found with nonlinear FE analysis. Hence, the application of boundary conditions in this case is very important. 
Finally, a parametric study was performed to investigate the effects on the flexural behaviour under buckling of castellated timber beams having different shapes of web openings. The study has shown that the buckling had a considerable effect on the mechanical strength and failure modes of the castellated beams, where the failure modes were caused by distortional buckling. It is also shown that the nonlinear FE analysis gives a considerable decrease in the load capacity of castellated beams.

Further investigations are now in progress to extend these FE models with the hope of simulating the flexural behaviour of castellated beams using various geometrical and loading conditions and to provide more information for engineering applications used in timber industry.

\section{REFERENCES}

[1] Harte, A.M. \& Baylor, G., Structural evaluation of castellated timber I-joists. Engineering Structures, 33, pp. 3748-3754, 2011.

https://doi.org/10.1016/j.engstruct.2011.08.011

[2] Baylor, G. \& Harte, A.M., Finite element modelling of castellated timber I-joists. Construction and Building Materials, 47, pp. 680-688, 2013. https://doi.org/10.1016/j.conbuildmat.2013.05.076

[3] Ellobody, E., Nonlinear analysis of cellular steel beams under combined buckling modes. Thin-Wall Structures, 52, pp. 66-79, 2012.

https://doi.org/10.1016/j.tws.2011.12.009

[4] Liu, T.C.H. \& Chung, K.F., Steel beams with large web openings of various shapes and sizes: finite element investigation. Journal of Construction Steel Research, 59, pp. 1159-1176, 2003. https://doi.org/10.1016/S0143-974X(03)00030-0

[5] Zirakian, T. \& Showkati, H., Distortional buckling of castellated beams. Journal of Constructional Steel Research, 62, pp. 863-871, 2006.

https://doi.org/10.1016/j.jcsr.2006.01.004

[6] Kerdal, D. \& Nethercott, D.A., Failure modes for castellated beams. Journal of Constructional Steel Research, 4, pp. 295-315, 1984.

https://doi.org/10.1016/0143-974X(84)90004-X

[7] Raftery, G.M. \& Harte, A.M., Nonlinear numerical modelling of FRP reinforced glued laminated timber. Composites Part B, 52, pp. 40-50, 2013.

https://doi.org/10.1016/j.compositesb.2013.03.038

[8] Raftery, G., Harte, A. \& Rodd, P., Qualification of wood adhesives for structural softwood glulam with large juvenile wood content. Journal of the Institute of Wood Science, 18(1), pp. 24-34, 2008.

https://doi.org/10.1179/wsc.2008.18.1.24

[9] Raftery, G., Harte, A. \& Rodd, P., Bond quality at the FRP-wood interface using wood laminating adhesives. International Journal of Adhesion Adhesives, 29(2), pp. 101-110, 2009. https://doi.org/10.1016/j.ijadhadh.2008.01.006

[10] Khelifa, M., Lahouar, M.A. \& Celzard, A., Flexural strengthening of finger-jointed Spruce timber beams with CFRP. Journal of Adhesion Science and Technology, 29(19), pp. 2104-2116, 2015.

https://doi.org/10.1080/01694243.2015.1057395 
[11] Khelifa, M., Auchet, S., Méausoone, P.J. \& Celzard, A., Finite element analysis of flexural strengthening of timber beams with Carbon Fibre-Reinforced Polymers. Engineering Structures, 101, pp. 364-375, 2015.

https://doi.org/10.1016/j.engstruct.2015.07.046

[12] Abaqus. Theory manual. Version 6.14. Providence, RI: Dassault Systèmes Simulia Corp.; 2016. 